\title{
O COMPARTILHAMENTO DE SABERES SOBRE O USO DA MODELAGEM PARAMÉTRICA E DA FABRICAÇÃO DIGITAL ENTRE CONTEXTOS FORMATIVOS E PROFISSIONAIS DE ARQUITETURA: RELATO DE CASO
}

SHARING KNOWLEDGE ABOUT THE USE OF PARAMETRIC MODELING AND DIGITAL MANUFACTURING BETWEEN TRAINING AND PROFESSIONAL ARCHITECTURE CONTEXTS CASE REPORT

Janice de Freitas Pires ${ }^{1}$, Adriane Borda Almeida da Silva ${ }^{1}$, Alexandre Berneira da Silva ${ }^{1}$, Ramile da Silva Leandro ${ }^{1}$

\section{RESUMO:}

Este artigo apresenta os resultados de ações que visam compartilhar experiências de reconhecimento e apropriação de técnicas de projeto paramétrico e fabricação digital com escritórios de arquitetura, desenvolvidas no âmbito da extensão universitária. Tais ações têm investido no estabelecimento de um diálogo com profissionais de arquitetura, atuantes na esfera local, sobre as potencialidades de tais técnicas para a resolução de problemas de projeto, no dia a dia da prática de arquitetura. Além da própria formação dos estudantes envolvidos nas ações, os participantes tiveram a oportunidade de refletir sobre a importância das práticas dos estágios obrigatórios e da extensão curricularizada, consideradas como veículos já institucionalizados e próprios para trocas efetivas de conhecimento e potencialização mútua entre o contexto acadêmico e profissional.

PALAVRAS-CHAVE: projeto de arquitetura; projeto paramétrico; extensão curricularizada; estágio curricular.

\section{ABSTRACT:}

This article presents the results of actions that aim to share experiences of recognition and appropriation of parametric design techniques and digital fabrication with architectural offices, developed within the scope of university extension. Such actions have invested in establishing a dialogue with architecture professionals, active in the local sphere, about the potential of such techniques for solving design problems in the daily practice of architecture. In addition to the training of the students involved in the actions, the participants had the opportunity to reflect on the importance of mandatory internship practices and curricular extension practices, considered as already institutionalized vehicles for effective exchange of knowledge and mutual enhancement between the academic context and professional.

KEYWORDS: architectural design; parametric design; outreach; curricular internship.
${ }^{1}$ Universidade Federal de Pelotas
Fonte de Financiamento: Pro-reitoria de Extensão e Cultura da Universidade Federal de Pelotas (PREC).

Conflito de Interesse: Declarar não haver.

Ética em Pesquisa: Declara não haver necessidade.

Submetido em: 07/04/2021 Aceito em: 29/08/2021

How to cite this article:

PIRES, J. F, SILVA, A. B. A., SILVA, A. B., LEANDRO, R. S.. O compartilhamento de saberes sobre o uso da modelagem paramétrica e da fabricação digital entre contextos formativos e profissionais de arquitetura: relato de caso. Gestão \& Tecnologia de Projetos. São Carlos, v17, n1, Ano 2022. 


\section{INTRODUÇÃO}

Nos últimos anos, junto ao processo formativo de arquitetura, vários esforços têm sido empreendidos para a apropriação de práticas que conectam o desenho paramétrico com a fabricação digital (Celani e Sedrez, 2018). Entretanto, em nível local e nacional, ainda é difícil perceber os efeitos do reconhecimento e/ou reflexão sobre o uso e/ou pertinência da implementação destas práticas para além dos espaços acadêmicos.

Particularmente, junto ao ambiente acadêmico em que se insere este trabalho, as práticas projetuais estabelecidas em escritórios avançam para o uso, por exemplo, da parametrização dirigida ao gerenciamento da informação, mas ainda sem estarem permeadas por processos generativos ou também envolvendo a fabricação digital.

Esta percepção é conformada por meio do acompanhamento da prática de estágios de estudantes de arquitetura em escritórios e empresas de arquitetura, design e engenharia locais, sem, contudo, haver dados já sistematizados para quantificar algum percentual sobre o cenário do entorno imediato quanto a este avanço. De qualquer maneira, ainda existe uma distância entre os estudos teóricos, acadêmicos e exploratórios, sobre o tema desenho paramétrico e fabricação digital e a realidade de aplicação ao campo da produção de arquitetura. No âmbito formativo local, em termos curriculares, é muito recente a inclusão destas técnicas (a partir de 2012) e isto tem ocorrido de maneira sistemática em disciplinas introdutórias de representação. Desta maneira, os profissionais advindos deste contexto acadêmico vivenciaram problemas didáticos, porém centrados no campo da geometria, área de conhecimento que tem enfrentado certa descontinuidade de investimento em disciplinas de projeto propriamente ditas. Mesmo que os exercícios de introdução ao desenho paramétrico estivessem acompanhados de um discurso para situar a abrangência em todo campo da arquitetura, as práticas possíveis junto às disciplinas de início de curso envolvem essencialmente parâmetros geométricos. Neste cenário, desde 2012, passou a ocorrer a formação particularizada de alguns estudantes, por meio de projetos de pesquisa ou extensão específicos, ou ainda o reflexo da formação de estudantes que participaram de intercambios com escolas de arquitetura estrangeiras (por meio do Programa Ciências Sem Fronteiras), mas de maneira muito pontual.

A partir de Llach e Burbano (2020) tem-se uma provocação importante sobre como ambientes acadêmicos e profissionais reagem frente ao avanço da ciência, tecnologia e inovação, e como este avanço é um processo complexo, especialmente observando enfoques de "transferência entre um Norte desenvolvido e um Sul subdesenvolvido o qual persegue uma sempre evasiva modernidade digital." (tradução nossa, p.15). Os referidos autores reconhecem um repertório de estudos, de análises bibliométricas, que permitem observar como tem ocorrido a disseminação do emprego de técnicas de desenho paramétrico e também da difusão do que se configuram hoje como FABLABs latino-americanos. Entretanto, atentam para a necessidade de compreender os "detalhes, matizes e pontos de inflexão" de diferentes realidades que podem "desestabilizar a universalidade e centralidade dos sistemas tecnológicos".

Argumentam sobre a necessidade de observar as "especificidades histórica, material e estética dos sistemas informáticos" para reconsiderar o "enfoque de uma computação universal" para um enfoque de "computações plurais e situadas" (Lhach e Burbano, 2020, p.17).

Entende-se o espaço da extensão universitária como um lugar possível para dar eco a estes questionamentos, ultrapassando o propósito de "difusão" de um conhecimento novo para a compreensão da pertinência de sua apropriação e significação. A partir deste entendimento, em 2018, foi constituído o projeto PRO_ACORDA: PROmoção de Ações e de COmpartilhamento de experiências de empreendedorismo e inovação na área de Representação (fabricação digital 
e desenho paramétrico) para o Projeto em Design e Arquitetura. Trata-se de um Projeto desenvolvido junto ao Grupo de Estudos para o ensino e aprendizagem em Gráfica Digital (GEGRADI), da Faculdade de Arquitetura e Urbanismo (FAURB) da Universidade Federal de Pelotas (UFPel), o qual tem o objetivo de estabelecer um espaço de aprendizagem compartilhada, entre estudantes e profissionais, sobre fabricação digital e desenho paramétrico, temas estes que hoje permeiam a prática projetual e construtiva de arquitetura e design.

A abordagem do desenho paramétrico possibilita atribuir relações entre os elementos de um projeto, podendo este ser controlável por meio da modelagem associativa e da variação de parâmetros (Schumacher, 2018). Este método tem o propósito de desencadear um conjunto de soluções que respondam a tais relações, gerando formas emergentes, com potencial generativo (Kolarevic, 2003).

O PRO_ACORDA visa uma aproximação entre os polos da teoria (estudo de referenciais de arquitetura paramétrica e fabricação digital) e da prática dessas ações (o fazer através de oficinas e discussões com escritórios de arquitetura). Desta maneira, busca-se intensificar as conexões entre o 'saber' e o 'saber-fazer', nos termos da "Teoria Antropológica da Didática" (Chevallard, 1999). Esta teoria busca compreender e explicitar a gênese da atividade humana a partir da noção estruturada de um saber. Este Projeto extensionista tem configurado ações formativas, informativas e colaborativas, entre a academia e profissionais de escritórios de arquitetura e design, para constituir uma dinâmica de interação que promove a atualização, avaliação e possível validação do uso das técnicas de desenho paramétrico e de fabricação digital. 0 projeto trata de investir na promoção de momentos que auxiliem a construção de uma cultura de reconhecimento de tais saberes simultaneamente na academia e nos escritórios de arquitetura.

Para a academia o Projeto se configura como um espaço que promove vivenciar momentos de reflexão/produção, com propósitos inovadores, imersos em um ambiente profissional, como um escritório de arquitetura ou um estúdio de design. Para a atividade profissional, o Projeto se apresenta como uma oportunidade de refletir/contrapor as práticas já estabelecidas de projeto com as de desenho paramétrico e fabricação digital, ainda com caráter inovador, observando a pertinência em realizar esforços para uma atualização e/ou exploração das referidas práticas. Para ambos, representa uma forma de ensino e aprendizagem que nasce da interação entre as duas esferas do conhecimento, como descrito em Chevallard (1999), visando entender as técnicas projetuais abordadas dentro da instituição acadêmica e transformá-las, adaptá-las, repensá-las a partir da vivência fora de tal ambiente. Igualmente tem a intenção de promover a reflexão no âmbito desses escritórios, atuando na identificação de problemas apropriados ao uso de tais tecnologias, atribuindo um significado efetivo. Por exemplo, para a dinâmica de um escritório de arquitetura, busca promover a reflexão sobre problemas que no momento da ação estão sendo resolvidos com as técnicas tradicionais de projeto e constituir um processo aberto, dialogado, em que o projetista do lugar problematize/vivencie a lógica da transposição para o desenho paramétrico. Isto pode permitir aos estudantes envolvidos e aos profissionais compreenderem que os resultados, com este método de projeto, se referem a um conjunto de soluções que pode ser replicado a outros problemas similares, de maneira automatizada, a partir de um raciocínio projetual, representado por meio de um sistema de projeto (programação visual), mantendo o caráter inovador como pressupõe o processo projetual de arquitetura.

Neste trabalho, registra-se o histórico da conformação deste projeto extensionista para contextualizar e justificar o método de estudo adotado e aperfeiçoado, e apresentam-se os resultados das ações até então promovidas junto a escritórios de arquitetura, ocorridas entre o primeiro semestre de 2019 e junho de 2021. Com isto, buscou-se apresentar reflexões, 
concernentes ao diálogo travado entre "teoria e prática", entre "saber" e "saber fazer". Tratamse assim de reflexões realizadas a partir de atividades diferenciadas para a prática de arquitetura em lugares específicos e situados.

\section{REFERENCIAL TEÓRICO}

Os referenciais que dão suporte a este projeto advêm do campo da Didática, para compreender que um mesmo conhecimento é tratado de maneira diversa quando situado em um momento essencialmente formativo ou em um profissional; advêm do campo da extensão universitária, para compreender a importância da indissociabilidade entre ensino, pesquisa e extensão e da interação dialógica necessária entre academia e sociedade (onde se insere a prática profissional situada) e, logicamente, do conhecimento específico que o estudo está focado, já mencionado na introdução.

A Teoria da Transposição Didática, de Chevallard (1991) postula que um saber, ao transitar entre diferentes instituições, sempre é afetado, transformado para adaptar-se ao meio científico, profissional ou de ensino. Para esta adaptação, este saber é reestruturado e poderá estar enfatizado em um ou mais de seus elementos teóricos, técnicos e tecnológicos. Segundo o mesmo autor, no meio científico é privilegiada a veiculação do "saber" propriamente dito, cuja estrutura está centrada nos elementos "teoria" e "tecnologias"; junto à atividade profissional é normalmente veiculado o "saber-fazer", centrado nos elementos "problemas" e "técnicas"; em um contexto educativo faz-se necessário contemplar toda a estrutura, desta maneira, incluindo os blocos do "saber" e do "saber-fazer", reconhecidos a partir da Teoria Antropológica da Didática (Chevallard, 1999).

Faz-se pertinente esta teoria, justamente frente ao propósito do Projeto de compreender e buscar explicitar saberes profissionais, relativos ao exercício de projeto de arquitetura, associados a um saber-fazer cotidiano, específico e situado, e de dialogar com a estrutura de saber que está sendo veiculada no âmbito formativo envolvido. Aqui, com o foco em saberes possíveis de serem relacionados com as tecnologias de modelagem paramétrica e fabricação digital, a partir de uma abordagem simultânea das técnicas de resolução de problemas e do saber propriamente dito (teorias e tecnologias).

O Plano Nacional de Política da Extensão Universitária (PNPEU) está formulado para promover a interação transformadora entre Universidade e outros setores da sociedade. Para tanto, este Plano traz orientações para a estruturação e implementação das ações de Extensão Universitária, tais como: Interação Dialógica; Interdisciplinaridade e Interprofissionalidade; Indissociabilidade Ensino-Pesquisa-Extensão; Impacto na Formação do Estudante; e Impacto e Transformação Social. Sob estas diretrizes, a Universidade em que se desenvolve este projeto, recentemente institucionalizou a extensão curricularizada, por meio de carga horária integrada a disciplinas obrigatórias e destinada ao desenvolvimento de projetos extensionistas.

De maneira explícita, o Plano de Desenvolvimento Institucional, em sua resolução para estabelecer o processo de Curricularização da Extensão afirma que este processo pode contribuir (se for o caso) com o desenvolvimento socioeconômico e socioambiental da região, e particulariza alguns dos seus objetivos estratégicos associados a esta contribuição: (Apoiar iniciativas de inovação tecnológica e de desenvolvimento regional), (Assegurar o equilíbrio entre as ações do ensino, da pesquisa e da extensão) e (Intensificar as relações entre universidade e sociedade). (Universidade Federal de Pelotas/CONSUN № 13/2015). Segundo a Resolução no 6, do COCEPE/UFPel, de 03 de março de 2016, a iniciativa foi materializada pela caracterização da disciplina Requisitos Curriculares de Extensão, a qual deve estar 
devidamente associada a um Projeto de Extensão cadastrado na Pró-Reitoria de Extensão e Cultura da UFPel.

Em relação ao conhecimento específico, o estudo se desenvolve a partir da observação das estruturas de saber de referência (científico) e das estruturas utilizadas na prática de arquitetura (meio profissional) com o objetivo de constituir/reconhecer estruturas próprias para o meio acadêmico. Por intermédio da interação dos estudantes/estagiários com os escritórios são naturalmente estabelecidas conexões entre saberes científicos e profissionais, e podem ser potencializadas sob o campo de interesse deste Projeto . Neste processo, os docentes devem estar atentos aos movimentos transpositivos dos saberes, para coordená-los e atualizá-los constantemente com a pesquisa e o ensino, seguindo assim as diretrizes da extensão.

\section{ANTECEDENTES DO PROJETO}

O Projeto PRO_ACORDA teve seu início em abril de 2018 com a proposta de estabelecer um espaço para a PROmoção de Ações e de COmpartilhamento de experiências de empreendedorismo e inovação na área de Representação (fabricação digital e desenho paramétrico) para o Projeto em Design e Arquitetura. Ele deriva dos resultados do Projeto de Pesquisa ACORDA (Análise e COnstrução de Referenciais Didáticos para Arquitetura: uma abordagem para o Desenho paramétrico e para a prototipagem rápida), o qual investiu em construir uma infraestrutura conceitual e procedimental para a inserção das tecnologias de desenho paramétrico e fabricação digital junto a formação em arquitetura, na área de geometria e representação, da UFPel. A formação de bolsistas de iniciação científica e tecnológica associada a este projeto possibilitou a constituição de um grupo de estudantes interessados em explorar o uso das tecnologias referidas, o qual vislumbrou oportunidades empreendedoras, em especial pelo caráter inovador de métodos projetuais configurados a partir do uso do desenho paramétrico. Apoiado em iniciativas institucionalizadas, pela própria UFPel, promovidas pela Pró-Reitoria de Pesquisa, Pós-Graduação e Inovação, PRPPGI no campo da Inovação Tecnológica, este grupo foi selecionado e passou por um processo formativo para a criação de uma empresa incubada. Entretanto, mesmo diante da aprovação do Projeto de Incubação, inclusive já com ações experimentais realizadas no âmbito local, o grupo avaliou a necessidade de ainda haver um tempo de investimento para a geração de uma cultura de uso, de reconhecimento das potencialidades de tais tecnologias para que exista uma demanda que promova um processo sustentável para a atividade empresarial. Isto no que diz respeito à integração do desenho paramétrico à fabricação digital, onde esteve o principal interesse do grupo. Na época, as análises em relação à demanda específica para a fabricação digital, na escala do objeto de design e não propriamente de arquitetura, indicavam a viabilidade da empresa a ser incubada. Esta experiência foi relatada em BRUM e BORDA (2018, pág. 4):

A experiência de pré-incubação foi permeada por desafios, mas o principal esteve centrado na aplicação de conceitos estudados e testados em atividades de pesquisa. Dentro deste contexto a presença em uma incubadora de base tecnológica foi fundamental por apresentar processos, os quais deram subsídio para compreender a lógica e as necessidades do mercado, buscar processos viáveis para formatar um modelo de negócios inovador, escalável e rentável. Observou-se que pela complexidade e caráter inovador do tema, é preciso criar demanda diretamente aos profissionais que atuam na área de projetos de arquitetura e design. E, para isto, o primeiro passo é sensibilizar e gerar uma cultura de reconhecimento do desenho paramétrico e fabricação 
digital, para então gerar a demanda por produtos que se utilizem destes métodos. (BRUM, BORDA, 2018, p. 4)

A partir das reflexões advindas do envolvimento neste processo de incubação, é estruturado o PRO_ACORDA, com o propósito de estender os objetivos do Projeto de Pesquisa ACORDA para o âmbito da extensão universitária, configurando um espaço para que os profissionais de arquitetura e design, da cidade de Pelotas e Região, possam reconhecer e avaliar a pertinência do uso das tecnologias em questão em seus processos projetuais.

Há então, como ponto de partida, o objetivo de promover um processo compartilhado de aprendizagem e apropriação de conhecimentos que associam o desenho paramétrico à fabricação digital, considerando os conhecimentos prévios de ambos os contextos. Para isto, foram configuradas junto ao PRO_ACORDA, três tipos de ações: formativas, informativas e colaborativas entre a academia e profissionais de escritórios de arquitetura e design, com o objetivo de constituir uma dinâmica de interação dialógica que promova a atualização, avaliação e possível validação de tais conhecimentos para as práticas de projeto locais.

Desta maneira, o projeto investe na geração de uma cultura de uso de tais tecnologias a partir da promoção de momentos significativos tanto para academia quanto para o ambiente profissional. Para a academia, quer ampliar o espaço para vivenciar momentos de produção, com propósitos inovadores, imersos no cotidiano de um escritório de arquitetura ou de um estudio de design. Para o profissional, quer provocar a contraposição entre práticas já estabelecidas de projeto com as de caráter inovador. 0 Projeto quer, assim, observar a conveniência em realizar esforços para uma atualização das referidas práticas e ensejar, com isto, a identificação de problemas apropriados para uma formação acadêmica situada e reflexiva quanto ao uso do conhecimento aqui abordado.

É natural e prudente os sistemas educativos exigirem um processo de validação de saberes que por sua natureza pode ser lento e gradual. Cabe aos cientistas e aos profissionais contribuírem para fornecer dados para esta validação e legitimação. Entretanto, é fundamental que haja a sensibilidade e predisposição para perceber, identificar tais saberes emergentes. 0 campo da extensão universitária é propício para a configuração deste espaço de ação e observação. No documento inicial do Projeto PRO_ACORDA há o registro do propósito de estender o diálogo que se tem estabelecido em fóruns científicos ao meio profissional, para de maneira colaborativa formatar ações que reconfigurem as práticas de projeto, fortalecendo por sua vez o próprio fazer da extensão universitária. Oferecer cursos de atualização profissional a outros projetistas que não foram contemplados em seus currículos com este tipo de formação está em consonância com o papel da extensão universitária. Por outra parte, há que compreender as possibilidades do reconhecimento e uso de processos produtivos por meio da fabricação digital, já que poucas empresas da região dispõem dos equipamentos para tal.

Deve-se destacar ainda que o Projeto foi configurado em um momento anterior à institucionalização da extensão curricularizada. Entretanto, o advento deste tipo de extensão foi providencial para atribuir sustentabilidade ao próprio Projeto. Inicialmente a proposta pensava em contar com parcerias pontuais de casos isolados caracterizados pela oportunidade e conveniência da colaboração de escritórios e de estudantes. Por vezes contou-se com bolsistas de pesquisa, ensino e/ou extensão que haviam passado pelo Grupo de pesquisa e se envolvido na produção relativa ao tema "desenho paramétrico e fabricação digital". 0 Projeto se desenvolveu durante dois anos sem a condição de contar com tal institucionalização e desde o semestre 2019/01 planeja ações como atividades da disciplina Requisitos Curriculares de Extensão (RCE). Esta disciplina é caracterizada com 4 créditos e é oferecida a partir do segundo 
semestre de Curso, com o intuito de sensibilizar os estudantes para estarem atentos às possibilidades de serem agentes ativos neste processo por meio dos estágios acadêmicos, obrigatórios ou voluntários junto aos escritórios de arquitetura. Desta maneira, com as atividades da disciplina o Projeto tem a pretensão de promover o estabelecimento de parcerias para um reconhecimento das demandas profissionais locais de maneira mais específica. Isto traz para o Projeto a necessidade de também sistematizar os dados sobre onde os estudantes realizam seus estágios e logo, compreender se nestes lugares já há algum reconhecimento e uso dos conhecimentos aqui particularizados junto à prática projetual cotidiana. Em um primeiro momento, o Projeto buscou esta sistematização apenas junto aos lugares onde são realizados os estágios obrigatórios, em função do acesso a este tipo de informação facilitado pelo próprio Colegiado de Curso da (omitido). Entretanto, estes dados dizem respeito somente a informações como o nome dos lugares, número e nome dos estagiários recebidos em cada local e datas. Este tipo de dados é circunstancial e exige uma atualização contínua para gerar informações que adquiram transcendência para os objetivos deste Projeto. Faz-se necessário compreender as especificidades das atividades dos estagiários para identificar as oportunidades para o desenvolvimento do Projeto.

\section{METODOLOGIA}

Para atingir a totalidade dos objetivos propostos, o projeto está estruturado a partir de três tipos de ações:

1. Ações formativas: para o desenvolvimento das ações formativas são abordados os conceitos e técnicas de modelagem paramétrica associada à fabricação digital, a partir do estudo de casos de projeto de arquitetura de referência. Este tipo de estudo subsidia a estruturação de materiais didáticos, caracterizados como um dos produtos das atividades da disciplina de RCE. As ferramentas envolvidas até então são: Rhinoceros/Grasshopper como ambiente de modelagem paramétrica; corte a laser e impressão 3D, incluindo especialmente exercícios práticos. Estas ações são realizadas, por um lado, junto à própria disciplina (extensão curricularizada) - esfera intrainstitucional - e, por outro, valendo-se de cursos de extensão (educação continuada) - esfera interinstitucional - o que amplia para um público alvo de estudantes, docentes e profissionais de arquitetura e design. Nessa etapa, os envolvidos têm a oportunidade de trocar experiências, saberes e construir as bases para serem compartilhadas fora do ambiente acadêmico. Além dos estudantes matriculados na disciplina RCE, há bolsistas vinculados ao Projeto que, igualmente, se envolvem com tais atividades, e ficam responsáveis pela formação para a produção por fabricação digital, por processos de corte a laser e impressão 3D (método aditivo) desenvolvidos no laboratório do GEGRADI. No âmbito destas ações há o foco da compreensão da estrutura integral dos saberes tratados: saber propriamente dito e o saber-fazer.

2. Ações informativas: A partir da infraestrutura construída junto às ações formativas, a dinâmica é constituída pelo estabelecimento de um diálogo inicial com os profissionais de arquitetura para a apresentação do projeto PRO_ACORDA e para compartilhar as informações que exemplificam o uso dos conceitos e técnicas, aqui particularizados, em práticas de arquitetura em âmbito internacional e nacional. A primeira ação deste tipo foi realizada junto ao grupo diretor da Associação de Engenheiros e Arquitetos da cidade de Pelotas, no segundo semestre de 2018. 0 Projeto foi apresentado ao grupo, e, de maneira conjunta, avaliou-se a conveniência de abordar individualmente os escritórios que tradicionalmente fazem parte da rede de lugares onde os estudantes realizam os estágios curriculares. Em um segundo momento (primeiro semestre de 2019), realizou-se uma experiência piloto com a seleção de dois escritórios de arquitetura sob o critério de um acesso facilitado e receptividade, pelos profissionais responsáveis, para garantir a execução da ação de maneira imediata (para 
cumprir os tempos acadêmicos exigidos para a conclusão da disciplina). Como método para a seleção das demais ações, decidiu-se partir de uma lista de escritórios registrados junto aos relatórios dos estágios obrigatórios realizados pelos estudantes de arquitetura da Faculdade de Arquitetura e Urbanismo (FAURB), fornecida pelo Colegiado de Curso. Os estudantes bolsistas vinculados ao Projeto auxiliam na sistematização dos dados para elencar os escritórios a serem contatados para a aplicação das ações e preparam a infraestrutura para a sua execução. A ordem de abordagem para propor a ação está sendo realizada pelo critério de lugares que sediam um maior número de estagiários e com maior frequência, e está sempre dependente da receptividade.

Este tipo de ação originalmente esteve programado para ocorrer em formato de eventos, junto aos escritórios de arquitetura, para compartilhar os casos estudados pela equipe do PRO_ACORDA. Na medida do possível, estes casos passam a ser selecionados a partir do diálogo com os escritórios, utilizando-se também da aplicação de um instrumento de avaliação (questionário) para compreender as aplicações de interesse. Também são caracterizadas como ações informativas aquelas que buscam a detecção de casos de obras que começam a aparecer no cenário urbano, na tentativa de acompanhar os reflexos nas práticas e compreender como e de onde decorrem, se do próprio investimento do processo formativo aqui envolvido ou se advêm de outras situações (profissionais autodidatas/ estudantes que fizeram intercâmbio/projetos e/ou execução de profissionais contratados de outros lugares).

Para contextualizar o estudo são observados alguns dados quantitativos sobre o número de arquitetos registrados no Conselho de Arquitetura e Urbanismo (CAU) no cenário local, comparativamente aos cenários nacional, regional, e da capital da região.

3. Promoção de ações in loco: Estas ações são configuradas a partir da tentativa de imersão de especialistas/estudantes/estagiários em desenho paramétrico e fabricação digital nos escritórios de arquitetura e design. Por meio de parcerias, a ação busca identificar problemas cotidianos de trabalho que possam ser incrementados em seu potencial criativo ou de automatização, otimização e racionalização de processos produtivos. Inclui o esforço de identificar casos que ilustrem as vantagens, e viabilidade, de uso dos conceitos e procedimentos em questão para a realidade de cada arquiteto. Na medida do possível, o processo de seleção dos casos, para além das oportunidades, tenta diversificar os tipos de aplicações, como o design de elementos de fachadas, de mobiliário, de interiores, de paisagismo, abarcando assim as diferentes escalas de projeto, do detalhe ao urbano.

Todas as ações são promovidas envolvendo uma equipe, constituída de alunos, bolsistas, exbolsistas de iniciação científica e de extensão, os quais investiram em uma formação especializada nas tecnologias em questão e estão dispostos a adquirir uma capacitação para o empreendedorismo e a inovação a partir da aplicação destes conhecimentos junto à produção em arquitetura e design localmente situada.

Os objetivos do Projeto, como observado, vão além do alcance das atividades propostas no âmbito de uma disciplina. As ações a serem realizadas pelos estudantes estagiários, junto aos escritórios de arquitetura, são dependentes das ações prévias necessárias para a formação destes agentes e da construção de uma cultura de interesse no tema proposto. Desta maneira, a metodologia aqui especificada restringe-se, no momento, ao desenvolvimento das etapas formativas e informativas. As ações de detecção dos problemas e de desenvolvimento de experimentações associadas ao tema em questão, ações in-loco, deverão ter métodos e procedimentos flexíveis, com dinâmicas determinadas pelo próprio estágio de apropriação dos saberes tratados, do protagonismo, sensibilidade e receptividade, de ambas as partes envolvidas. 
Frente a isto, o projeto está sendo executado a partir de etapas que objetivam configurar e executar as ações formativas e informativas para logo avançar às ações in-loco:

1) Revisão bibliográfica: reconhecimento do estado da arte. Esta revisão trata de compreender o conceito de design paramétrico associado à fabricação digital a partir de Celani e Sedrez (2018) e Woodbury (2010) e, principalmente, busca identificar casos de projetos de arquitetura apoiados na associação destes conceitos, a partir de Burry \& Burry (2010).

2) Seleção e estudo dos casos de arquitetura ilustrativos das aplicações em desenho paramétrico e fabricação digital;

3) Apropriação de técnicas de desenho paramétrico e de fabricação digital;

4) Execução de protótipos de exemplificação;

5) Estruturação de um material didático como suporte à ação;

6) Aplicação da ação nos escritórios de arquitetura;

7) Elaboração e aplicação de um instrumento de avaliação das ações.

No primeiro semestre de 2020, o projeto teve que se adaptar ao cenário de pandemia do coronavírus, e de exigência de isolamento social, fazendo com que a interação, antes presencial e direta com os escritórios, ocorresse de maneira remota, uma exigência que foi regulamentada pela pró-reitoria de extensão da universidade em maio de 2020. Em função disto, as atividades mais significativas do projeto, neste período, foram as ações formativas e de estruturação de materiais didáticos para futuras apresentações nos escritórios, compreendendo assim todas as etapas, à exceção das duas últimas de aplicação e avaliação da interação, propriamente dita, com o ambiente profissional. As adaptações ocorreram especificamente nas duas últimas etapas, de aplicação e avaliação da interação com o ambiente profissional. 0 contato inicial com os escritórios permaneceu sendo via e-mail, com o envio dos materiais de apresentação do Projeto, porém já com a adição dos materiais formativos/informativos, sobre os casos estudados, em formato digital, texto e imagens, com a inclusão de um vídeo e um questionário. Este questionário, estruturado via Google Docs, para ser respondido pelos escritórios de arquitetura, aborda questões informativas sobre as experiências prévias dos profissionais com o tema, sobre a opinião deles relativa à importância do mesmo para o contexto de sua própria prática de arquitetura e sobre o interesse de haver algum envolvimento com o Projeto. Em 2021, para intensificar o diálogo com os escritórios, o contato está sendo feito por intermédio de entrevistas online, síncronas ou assíncronas, realizadas em um ambiente de web conferência ou diretamente no aplicativo WhatsApp por meio de áudios gravados.

\section{DESENVOLVIMENTO}

Este projeto está registrado junto à pró-reitora como um projeto do tipo integrado (ensino, pesquisa e extensão), portanto, contemplando os três tipos de ações descritas na metodologia. Trata-se de um Projeto que se propõe a ter continuidade, e, neste momento, encontra-se com término datado para 2025. Entretanto, por envolver um processo dialógico intra e extra institucional, a cada ação há a autoavaliação a qual pode indicar novos redirecionamentos, atentos às oportunidades emergentes no processo.

Desenvolvimento das Ações do tipo 1: formativas

De maneira sistemática, as ações formativas foram constituídas como carga horária da disciplina de Requisitos Curriculares de Extensão, com 4 horas semanais contando com a colaboração/formação de bolsistas, durante quatro semestres letivos, de 2019/02 a 2020/02. Estes momentos de formação estiveram centrados em exercícios de representação de 
geometrias empregadas na arquitetura contemporânea, como um primeiro contato com as técnicas de modelagem paramétrica e fabricação digital. Neste tipo de atividade, o grupo teve a oportunidade de refletir sobre as diferenças de métodos de projetos e construções de arquitetura que se utilizam do desenho paramétrico associado à fabricação digital, como também, por meio dos exercícios de representação, o grupo experenciou as facilidades e/ou dificuldades inerentes ao emprego destas técnicas, especialmente com a incorporação da linguagem de programação visual. 0 conjunto dos estudos já envolveu a configuração de objetos na escala do mobiliário, do edifício de arquitetura e também já avançou para o paisagismo. Tratou-se de promover a seleção de casos de estudo que envolvessem uma estrutura capaz de explicitar os problemas abarcados com tais técnicas, assim como, de explicar conceitos que tem justificado a importância destes avanços metodológicos e processuais no campo de projeto e construção de arquitetura. Entretanto, trata-se de uma construção conjunta e dialogada que deve ser retroalimentada pelo desenvolvimento dos demais tipos de ações.

As ações formativas da primeira edição da disciplina RCE, portanto já como extensão curricularizada, associada a este Projeto, ocorreram no semestre 2019/01, as quais envolveram três estudantes matriculados e um estudante/bolsista de extensão. Cabe ressaltar que o reduzido número de estudantes nesta disciplina de caráter extensionista é próprio da dinâmica proposta pela instituição, pois há um repertório destas disciplinas associadas a cada projeto extensionista desenvolvido no âmbito da Faculdade, sob diferentes temas, cujas vagas são determinadas de acordo com a característica do projeto. A disciplina se desenvolve com 1 hora/aula de orientação e tres de prática pelo estudante, semanalmente, por 17 semanas. 0 caso de estudo selecionado pelo grupo de matriculados foi o do Museu Louvre de Abu Dhabi, do arquiteto Jean Nouvel (Figura 1), considerado significativo em relação ao uso da abordagem do desenho paramétrico no processo de projeto. 0 caso estudado pelo bolsista foi do projeto de um mobiliário e envolveu a representação por desenho paramétrico e a fabricação digital. Ambos os estudos foram compartilhados pelos quatro estudantes, em especial o processo de representação de elementos por corte a laser.

A partir da análise da obra e dos discursos dos profissionais responsáveis, disponíveis em sites especializados de arquitetura e também pelo contato por email com membros da equipe de desenvolvimento da obra, os estudantes buscaram compreender como, por intermédio de técnicas paramétricas de modelagem e de fabricação digital, o projeto foi desenvolvido. Foram destacados os aspectos conceituais e generativos de projeto, suas associações com a cultura, paisagem e clima do lugar, o tipo a geometria e de solução estrutural.

Figura 1. Museu do Louvre de Jean Nouvel.

Fonte:

Nazar Skalatsky, Agnieszka Kowalczyk, Dmitry Novikov, Alvaro Pinot

(https://unsplash.com/s/photos/lou vre-abu-dhabi)

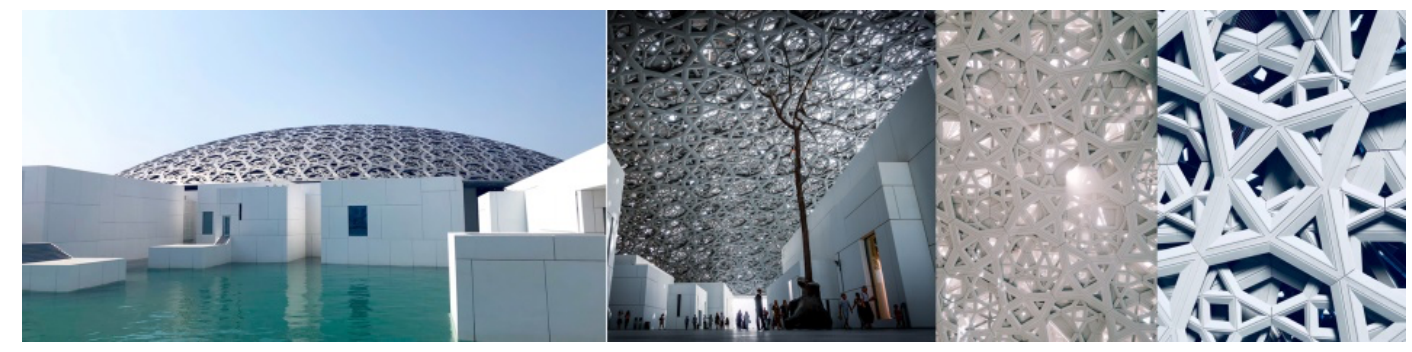

Os exercícios de representação, digitais e físicos, ficaram centrados no desenho do padrão de perfurações da cúpula do Museu do Louvre, para ilustrar o efeito de "chuva de luz" que é produzido pela sobreposição de várias camadas e escalas de tal desenho. A imagem inferior esquerda da Figura 2 ilustra o modelo físico, executado por corte a laser, para compreender os 
procedimentos recursivos aplicados à geometria destas camadas para gerar o fenômeno lumínico controlado, de maneira específica, em cada parte do amplo espaço coberto por esta imensa cúpula, cuja base tem o diâmetro de $180 \mathrm{~m}$.

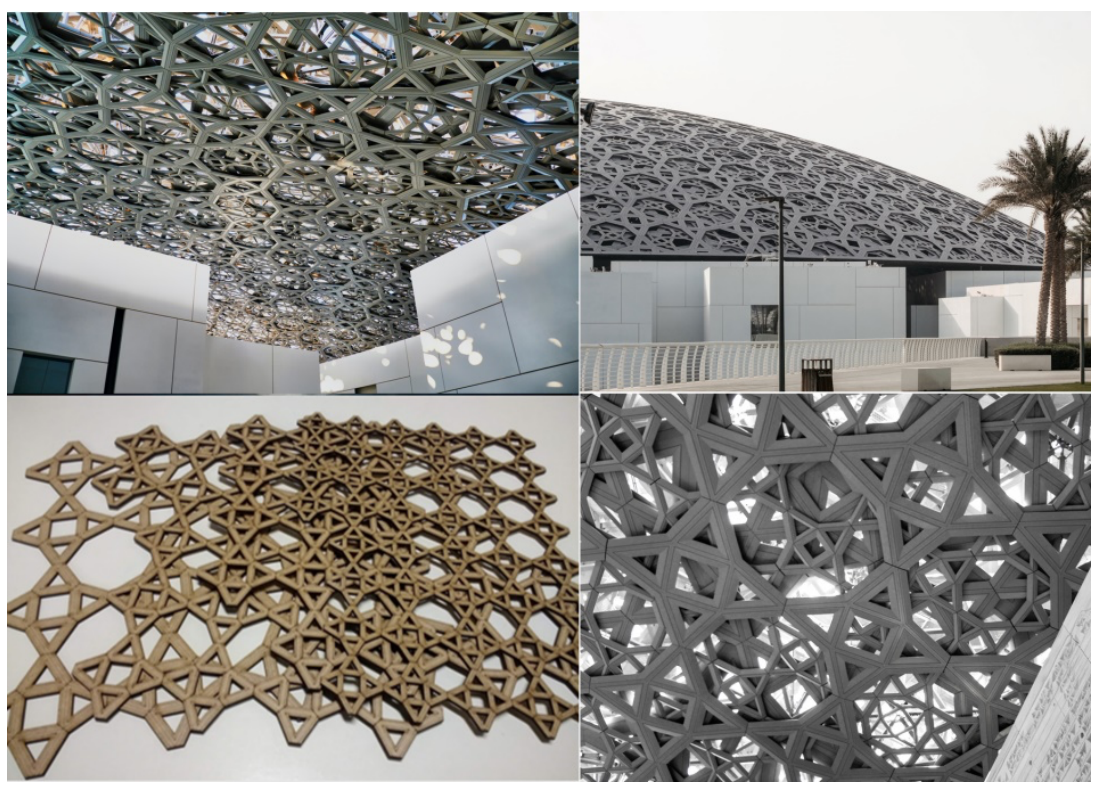

O estudo na escala do mobiliário envolveu a concepção parametrizada, apoiada em estudos de antropometria de Panero e Zelnik (2014). A Figura 3 ilustra a lógica considerada para interpolar seções de um banco correspondentes com as curvas ergonômicas apresentadas em Pronk (2003), para configurar uma forma flexível em relação ao uso deste objeto.
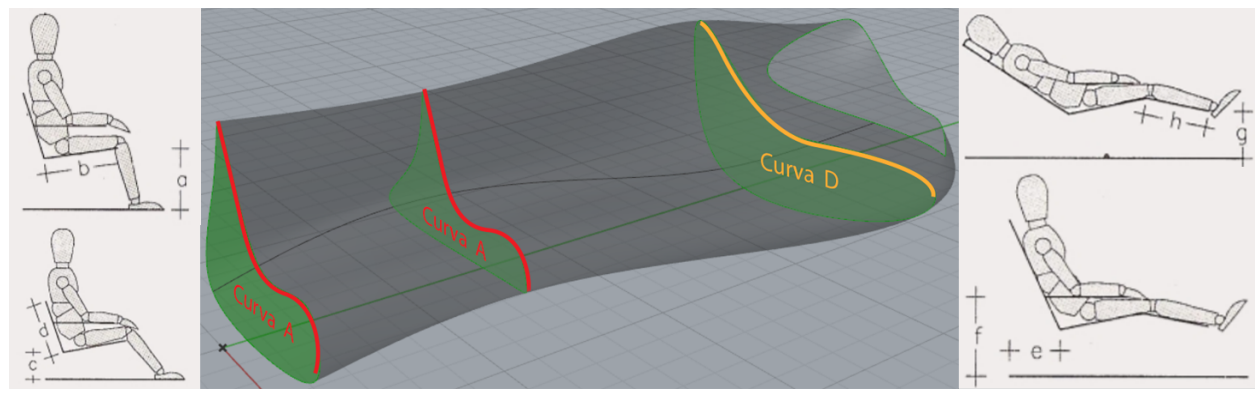

0 projeto do referido banco foi representado a partir da técnica de planos seriados e materializado por corte a laser, em MDF, montado manualmente por encaixe de suas partes seccionadas (Figura 4).
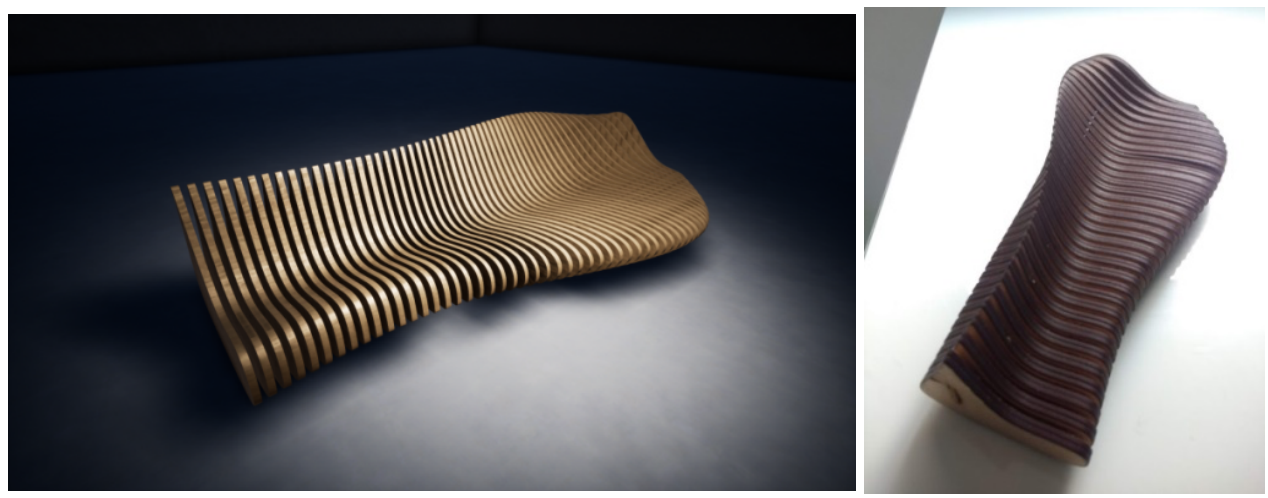

Figura 2. Padrão da cobertura do Museu do Louvre e 0 resultado do exercício de reprodução por corte a laser.

Fonte: A por Kent Tupas e B por Muhammed Shazin (https://unsplash.com/s/photo s/louvre-abu-dhabi); C por elaboração própria; e Figura D por Tasos Lekkas (https://pixabay.com/images/s earch/louvre\%20abu\%20dhabi ).

Figura 3. Banco parametrizado a partir de curvas ergonômicas.

\section{Fonte:}

estudo de ergonomia por Pronk (2003) e modelagem por elaboração dos autores.

Figura 4. Modelo digital e protótipo de um banco parametrizado desenvolvido por corte a laser

Fonte:

Elaboração própria 
Estes dois casos de estudo foram sistematizados e estruturados com uma linguagem textual e visual em formato digital e impresso (folder), para serem caracterizados como objetos de aprendizagem de apoio as demais ações formativas e informativas. 0 material produzido em relação ao Museu do Louvre aborda a história, o contexto e o conceito do projeto, na tentativa de exemplificar a abrangência da aplicação, enquanto que o material relativo ao banco foi compreendido como exemplo potencial para uma aproximação com o ambiente profisssional imediato, em função de sua aplicabilidade de execução na região.

As ações da segunda edição da disciplina, semestre 2019/02, contaram com apenas uma estudante matriculada e ficaram centradas na revisão bibliográfica e em exercícios com um mobiliário criado por um designer, replicando a trajetória de aprendizagem do estudo de caso do banco da ação anterior. No primeiro semestre de 2020, já na terceira edição da disciplina RCE, as ações formativas voltaram a contemplar um grupo de quatro estudantes (três matriculados na disciplina e uma bolsista), replicando o método de aprendizagem ao passo de produzir materiais de exemplificação de aplicações em desenho paramétrico e fabricação digital na arquitetura. Entretanto, desta vez, cada estudante adotou um projeto de referência em particular, gerando assim três casos de estudo (casos 1, 2 e 3) e a estudante/bolsista abarcou o estudo de dois projetos (casos 4 e 5). Na quarta edição da disciplina, no segundo semestre letivo de 2020/02, as ações contaram novamente com apenas um estudante matriculado em RCE, o qual produziu mais um caso de estudo (caso 6).

Os seis casos de estudo desenvolvidos nos semestres letivos 2020/01 e 02 estão listados na Figura 5. Cada um deles está associado a conceitos e justificativas, relativos ao uso de tais técnicas, enfatizados nos discursos dos próprios projetistas (discursos identificados na etapa de revisão bibliográfica realizada por cada estudante). Aparecem conceitos e propósitos como sustentabilidade, otimização estrutural, controle da economia de material, do consumo energético, redução da energia artificial consumida, melhor uso dos recursos naturais, como os decorrentes dos estudos de insolação. Aparecem também como potencialidade de adoção de sistemas generativos a exploração da biônica (imitação das formas orgânicas) e a simulação do estresse das superfícies para a otimização estrutural.

Os casos 1, 2, 3 e 6 foram sistematizados em formato de apresentação (slides) e não possuem material explicativo em vídeo. Os casos 4 e 5 (marcados com um fundo cinza) foram estudados e modelados pela bolsista do projeto, entre agosto e outubro de 2020 e foram sistematizados no formato de apresentação (slides) e possuem materiais explicativos no formato de vídeo. 


\begin{tabular}{|c|c|c|c|}
\hline Projeto & Conceito do projeto & Parametrização & Modelage \\
\hline & $\begin{array}{l}\text { Sistema solar auto suficiente e } \\
\text { construção multiescalar com um } \\
\text { componente modular de fachada } \\
\text { para apoiar placas fotovoltaicas. }\end{array}$ & $\begin{array}{l}\text { Variaçães de angulações da } \\
\text { incidência da luz solar, por meio } \\
\text { da modificação dos parâmetros } \\
\text { geométricos do módulo. }\end{array}$ & (1) \\
\hline $\begin{array}{l}\text { Caso 1: Pavilhão } \\
\text { Endessa - laas } \\
\text { Escritorio de Arquitetura, } \\
\text { 2011, Barcelona. } \\
\end{array}$ & $\begin{array}{l}\text { Sustentabilidade e aproveitamento } \\
\text { da luz natural. }\end{array}$ & & \\
\hline & $\begin{array}{l}\text { Projeto de retrofit comercial, edificio } \\
\text { de escritórios. }\end{array}$ & $\begin{array}{l}\text { Superficie gerada por um } \\
\text { conjunto de pontos no espaço. }\end{array}$ & \\
\hline & $\begin{array}{l}\text { Principios: Expressão diferenciada } \\
\text { na fachada e integração dos } \\
\text { espaços; }\end{array}$ & $\begin{array}{l}\text { Variações da superficie pela } \\
\text { variação no número de pontos } \\
\text { geradores e de sua localização }\end{array}$ & \\
\hline $\begin{array}{l}\text { Caso 2: Edificio Dear } \\
\text { Jingumae - Amano Design } \\
\text { Office, 2014, Tóquio. }\end{array}$ & $\begin{array}{l}\text { Expressão suave, destaque no } \\
\text { entorno edificado. }\end{array}$ & $\begin{array}{l}\text { no espaço. } \\
\text { Variaços nos parâmetros de } \\
\text { seçâa da superficie. }\end{array}$ & \\
\hline $\begin{array}{l}\text { Caso 3: Nawa -Arquiteto } \\
\text { OSKAR ZIET, 2014, } \\
\text { Daliowa em Wroclaw }\end{array}$ & $\begin{array}{l}\text { Pavilhão para o European Capital } \\
\text { of Culture, evento com o conceito } \\
\text { principal de "Metamorfose Cultural". } \\
\text { Forma orgânica, inspirada na } \\
\text { biônica. }\end{array}$ & $\begin{array}{l}\text { Arcos que variam de forma e } \\
\text { tamanho para encontrar uma } \\
\text { forma orgânica otimizada. } \\
\text { Simulação da aplicação da } \\
\text { técnicafisica denominada..... }\end{array}$ & $=$ \\
\hline & $\begin{array}{l}\text { Pavilhão para exposição do Salão } \\
\text { Internacional do Automóvel. Hoje } \\
\text { encontra-se em Munique abrigando um } \\
\text { café. }\end{array}$ & $\begin{array}{l}\text { Uso da técnica de modelagem } \\
\text { metaballs, que está relacionada } \\
\text { ao mecanismo da mitose } \\
\text { celular. }\end{array}$ & $\begin{array}{l}\text { lariação das } \\
\text { isocurvas }\end{array}$ \\
\hline $\begin{array}{l}\text { Caso 4: BMW BUBBLE } \\
\text { PAVILION -Arquiteto } \\
\text { Bernard Franken, } 1999, \\
\text { Frankfurt. }\end{array}$ & $\begin{array}{l}\text { Assemelha-se a gotas d'água prestes a } \\
\text { se mergirem. } \\
\text { Uso de ferramentas digitais para } \\
\text { otimizar o estresse da superficie. }\end{array}$ & $\begin{array}{l}\text { Variações em parâmetros de } \\
\text { interação dinâmica } \\
\text { geometria. }\end{array}$ & $=$ \\
\hline & $\begin{array}{l}\text { Seis estruturas de madeira que ocupam } \\
\text { a Plaza de la Encarnación, que abrigou } \\
\text { um convento e um mercado público, } \\
\text { ambos demolidos em } 1983 \text {. }\end{array}$ & $\begin{array}{l}\text { A parametrização recria tanto a } \\
\text { forma curva da estrutura como as } \\
\text { seçōes em madeira constituintes }\end{array}$ & $=$ \\
\hline $\begin{array}{l}\text { Caso 5: METROPOL } \\
\text { PARASOL -Arquiteto } \\
\text { Jürgen Mayer, 2004, } \\
\text { Sevilha. } \\
\end{array}$ & $\begin{array}{l}\text { É inspirada nas cúpulas da cateral e na } \\
\text { arborização da praça vizinha, a Plaza } \\
\text { del Cristo de Burgos. Abriga em seus } \\
\text { cinco possos, Iojas, lanchonetes, um } \\
\text { restaurante, o novo mercado municipal, } \\
\text { um mirante e um museu subterrâneo }\end{array}$ & $\begin{array}{l}\text { da estrutura, que foi construida } \\
\text { com placas de abeto laminado, } \\
\text { representando cortes ortogonais } \\
\text { com o auxilio de uma máquina de } \\
\text { corte CNC. }\end{array}$ & 㻎 \\
\hline$\frac{1}{2}$ & $\begin{array}{l}\text { Projeto vencedor da Competição } \\
\text { internacional de } 2009\end{array}$ & $\begin{array}{l}\text { A parametrizaçãa permite definir } \\
\text { áreas de densificaçấo do padrâao } \\
\text { Voronoi, associadas a proposta }\end{array}$ & \\
\hline & $\begin{array}{l}\text { Um algoritmo de Voronoi foi utilizado } \\
\text { parametricamente para criar ilhas de } \\
\text { atividades planejadas e circulações } \\
\text { entre estas ilhas. }\end{array}$ & $\begin{array}{l}\text { Voronol, associadas a proposta } \\
\text { de setorização dada pela } \\
\text { populaçâa local, caracterizando } \\
\text { os diferentes usos para o projeto } \\
\text { da pracasto }\end{array}$ & 20 \\
\hline $\begin{array}{l}\text { Caso 6: PRAÇA } \\
\text { GLORIETA JUAN } \\
\text { CARLOS - Arquiteto } \\
\text { xxx, 2009, Mula, } \\
\text { Espanha. }\end{array}$ & $\begin{array}{l}\text { A setorização final foi definida a partir } \\
\text { de consultas públicas à população } \\
\text { local, por meio de um software } \\
\text { interativo com o qual foi possivel propor } \\
\text { alternativas projetuais. }\end{array}$ & & $s$ \\
\hline
\end{tabular}

Foi possível também que docentes e ex-bolsistas associados ao PRO_ACORDA se envolvessem com disciplinas de projeto propriamente ditas, para além das disciplinas de geometria e representação. Este envolvimento se deu ao assumirem a responsabilidade de um Atelier de Projeto, sob o tema de desenho generativo (Celani, Vaz e Pupo, 2013). Este Atelier é uma disciplina curricular de caráter eletivo, com 6 horas semanais, oferecida para estudantes que cursam a partir do quinto semestre. Isto ocorreu durante dois semestres consecutivos (2018/02 e 2019/01), cada um deles com oito alunos matriculados. Para apoiar o desenvolvimento desta disciplina, foram configuradas oficinas com exercícios em programação visual/Grasshopper para a promoção de processos criativos e de controle da forma geométrica, associados aos exercícios de fabricação digital. Estas oficinas podem ser compreendidas, com algum detalhe, em (omitido). A oportunidade de ministrar disciplina de Projeto acelerou a configuração de uma coleção de materiais didáticos focados em exercícios com as técnicas envolvidas e ampliou o número de estudantes com este tipo de formação, em um momento com maior potencial para agregar agentes ativos neste esforço de estabelecer uma cultura de reconhecimento e uso de tais saberes, tendo em vista a exigência dos estágios curriculares e voluntários já neste estágio do curso (também a partir do quinto semestre).

A partir dos dados sistematizados na Tabela 1 pode-se observar que foram envolvidos no conjunto das ações formativas, até então realizadas, um total de 28 estudantes de arquitetura.
Figura 5. Estudos de caso de arquitetura representados em 2020/01 e 02 pelos estudantes participantes do projeto Pro_Acorda.

Fonte: Autores 
Tabela 1. Dados sobre os números de estudantes envolvidos em ações formativas

Fonte: Autores

Tabela 2. Dados sobre o número de arquitetos ativos no lugar das ações

Fonte: CAU (2021)
Tabela 3. Dados sobre os números de estudantes envolvidos em estágios.

Fonte: Dados do colegiado do curso de Arquitetura e Urbanismo, UFPel.
Este número representa $8 \%$ dos 336 estudantes matriculados na Faculdade envolvida (semestre 2020/02), a qual conta, normalmente, com o ingresso de 34 estudantes por semestre. Este percentual de $8 \%$ cai para $3,5 \%$ se forem considerados apenas os 12 estudantes associados diretamente às ações de caráter extensionista (específicas do PRO_ACORDA).

\begin{tabular}{|r|r|r|r|r|r|r|r|}
\hline QUANTIDADE DE ESTUDANTES ENVOLVIDOS EM AÇÕES FORMATIVAS \\
\hline ANO LETIVO & 2018 & 2019 & 2020 & TOTAL \\
\hline SEMESTRE & 02 & 01 & 02 & 01 & 02 & \\
\hline MATRICULADOS NA DISCIPLINA RCE & & 3 & 1 & 3 & 1 & 8 \\
\hline BOLSISTAS E EXBOLSISTAS & 1 & 1 & 1 & 1 & 4 \\
\hline OFICINAS PARA O ATELIER DE PROJETO & 8 & 8 & & & & 16 \\
\hline TOTAL & 9 & 12 & 2 & 4 & 1 & 28 \\
\hline
\end{tabular}

Desenvolvimento das Ações do tipo 2: informativas

Alguns dados quantitativos foram sistematizados para compreender o cenário profissional de arquitetura na cidade. A Tabela 2 apresenta dados relativos ao número de arquitetos cadastrados no CAU. Observa-se que Pelotas em comparação com a capital de seu estado tem menos da metade de arquitetos ativos por cada 1000 habitantes, porém tem mais que o dobro em relação aos números do país como um todo, e está acima da média em termos estaduais.

\begin{tabular}{|c|c|c|c|c|}
\hline DADOS DO LUGAR & BRASIL & RIO GRANDE DO SUL & PORTO ALEGRE & PELOTAS \\
\hline $\begin{array}{r}\text { POPULAÇÃO ESTIMADA } \\
\text { (IBGE/2020) }\end{array}$ & 211.800 .000 & 11.422973 & 1.488 .252 & 343.132 \\
\hline $\begin{array}{r}N^{0} \text { DE ARQUITETOS } \\
\text { REGISTRADOS (CAU/2021) }\end{array}$ & 201.982 & 19.695 & 7.474 & 820 \\
\hline \multirow[t]{3}{*}{$\begin{array}{r}N^{N} \text { DE ARQUITETOS } \\
\text { REGISTRADOS/1000 HABITANTES }\end{array}$} & 0,953 & 1,724 & 5,021 & 2,38 \\
\hline & \multicolumn{3}{|c|}{ Nº DE ARQUITETOS REGISTRADOS E ATIVOS } & 691 \\
\hline & \multicolumn{3}{|c|}{ N DE ARQUITETOS REGISTRADOS E ATIVOS/1000 HABITANTES } & 2,013 \\
\hline
\end{tabular}

Os dados sistematizados na Tabela 3 auxiliam na compreensão dos tipos de lugares que tradicionalmente sediam os estágios curriculares realizados pelos estudantes junto a esta Faculdade, e estão associados aos números de estagiários em cada tipo por semestre, durante o período de desenvolvimento do PRO_ACORDA. Realizou-se uma análise destes dados entre 2015 e 2019 para identificar os lugares com potencial para serem abordados nas ações. A média da quantidade de estagiários identificada antes da pandemia COVID19 se mantinha distribuida de maneira equilibrada entre escritórios, construtoras e departamentos públicos. Deve-se destacar que as quantidades indicadas correspondem com a data de início do estágio de cada estudante, para não haver o problema de duplicação, tendo em vista que o número de horas pode ser distribuído em um ou mais semestres. Observou-se um incremento de quase $100 \%$ no número de estágios registrados em cada semestre do ano de 2020 e de mais de $200 \%$ no primeiro semestre de 2021, sem a manutenção de uma frequência equilibrada entre os três tipos de lugar e com diferenças de preponderância de um semestre para outro.

\begin{tabular}{|r|r|r|r|r|r|}
\hline QUANTIDADE E TIPO DE LUGAR DE ESTÁGIOS REGISTRADOS POR SEMESTRE \\
\hline ano letivo & 2015 a 2019 & 2020 & 2021 \\
\hline semestre & média/semestre & 01 & 02 & 01 \\
\hline ESCRITÓRIOS DE ARQUITETURA & 3 & 3 & 9 & 15 \\
\hline CONSTRUTORAS & 2 & 4 & 3 & 13 \\
\hline DEPARTAMENTOS PÚBLICOS & $\mathbf{3}$ & 7 & 3 & 6 \\
\hline TOTAIS & $\mathbf{8}$ & 14 & 15 & 34 \\
\hline
\end{tabular}


Os dados da Tabela 3 permitem subsidiar, de alguma maneira, estudos que buscam analisar os impactos da pandemia junto ao movimento da atividade profissional, porém fogem do escopo deste Projeto. Mas é inevitável comentar sobre as seguintes observações: no primeiro momento de pandemia houve um incremento que dobrou o número de estágios junto às construtoras e aos setores públicos; no segundo semestre deste período a média de estágios iniciados em escritórios triplicou; e, no terceiro semestre, ainda em tempos de pandemia, a média quadriplicou em relação àquela em tempos normais. Deve-se ressaltar também que há uma grande parte de estágios realizados pelos estudantes que não são oficializados junto à Faculdade, o que limita a utilização destes dados para estudos específicos sobre tais impactos. Entretanto, os dados referidos foram indispensáveis para constituir/atualizar a lista de escritórios e orientar a ordem para realizar os contatos para o envio de materiais informativos, para solicitar o acesso ao questionário que objetiva compreender cada perfil profissional e, ainda, para viabilizar as entrevistas complementares. Para a seleção do público alvo das ações, até então se deu prioridade para os escritórios, pelo acesso mais facilitado quanto à atenção às questões burocráticas necessárias para abordar órgãos públicos (prefeituras e universidades) e, de certa maneira, as construtoras.

As ações informativas realizadas no primeiro semestre de 2019 envolveram dois escritórios de arquitetura locais (denominadas de ações 1 e 2) e foram realizadas a partir do compartilhamento dos estudos sobre o processo de projeto relativo ao Museu Louvre de Abu Dhabi e do exercício de projeto do banco, casos ilustrados anteriormente junto à descrição das ações formativas. Foram realizadas pela mesma equipe dos quatro estudantes que desenvolveram tais estudos e que cursavam na época o terceiro semestre da Faculdade de Arquitetura.

Ambos os escritórios trabalham simultaneamente com projetos de arquitetura e de interiores, coordenados por profissionais arquitetos advindos, em sua maioria, da Faculdade de Arquitetura e Urbanismo da Universidade Federal de Pelotas, em um período em que estes saberes ainda não eram veiculados no currículo. Entretanto, um destes escritórios (da ação 2) esteve representado por uma arquiteta que já possuia um conhecimento prévio, tanto em desenho paramétrico como em fabricação digital, por decorrência de uma formação como especialista na área de gráfica digital, obtida na mesma instituição de ensino que abriga o projeto de extensão. 0 outro escritório participou da ação 1 com uma equipe formada por seis arquitetas.

O contato com os escritórios foi inicializado pelo envio de um e-mail, por parte dos estudantes, com um folder de apresentação do projeto e da equipe (Figura 6), contendo uma descrição e ilustração dos estudos de caso a serem compartilhados.

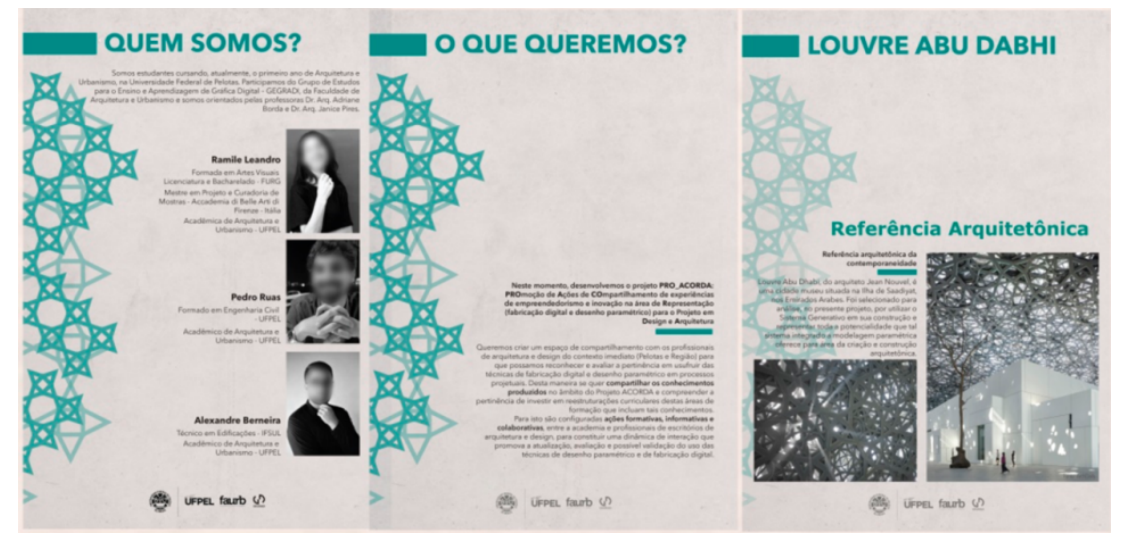

0 tipo de interação utilizado para as duas ações, presenciais, foi por apresentação oral auxiliada por mídia digital em forma de slides, sendo dividida em três partes distintas: - a primeira
Figura 6. Recortes do folder de apresentação aos escritórios de arquitetura, desenvolvido pelo grupo de estudantes do projeto, no primeiro semestre de 2019.

Fonte: Autores 
Figura 7. Aplicação das ações 1 e 2, em escritórios de arquitetura, no primeiro semestre de 2019.

Fonte: Autores.

Tabela 4. Respostas a quatro perguntas do questionário aplicado nos dois escritórios

Fonte: Autores.
O compartilhamento de saberes sobre o uso da modelagem paramétrica e da fabricação digital entre contextos formativos e profissionais de arquitetura: relato de caso

incluiu uma introdução ao desenho paramétrico e a explicação dos estudos de caso; a segunda apresentou os protótipos executados para a ação; e, a terceira, caracterizou-se por um espaço de trocas de informações. As imagens da Figura 7 registram alguns destes momentos.

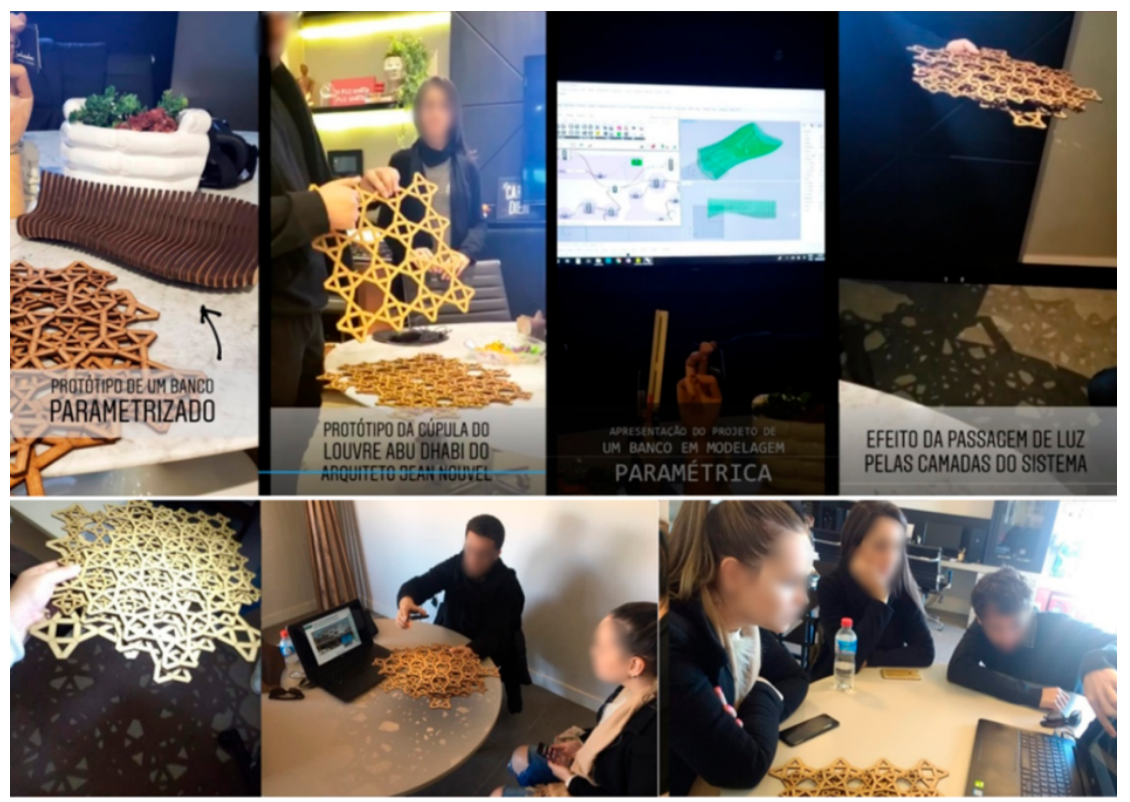

Os estudantes construíram e aplicaram um questionário on-line aos arquitetos envolvidos nas ações 1 e 2, como instrumento de avaliação. As perguntas que buscaram identificar os aspectos positivos e negativos percebidos por estes arquitetos sobre tais ações, para compreender possíveis impactos, assim como a autovaloração do conhecimento prévio acerca do desenho paramétrico. Na Tabela 4 são registradas as respostas a quatro perguntas do questionário, aplicado aos dois escritórios.

\begin{tabular}{lcc|} 
PERGUNTAS & AÇÃO 1 & AÇÃO 2 \\
\cline { 2 - 3 } & POUCO 1 - MUITO 5 \\
\hline $\begin{array}{l}\text { CONHECIA O CONCEITO DE DESENHO PARAMÉTRICO ANTES DA } \\
\text { AÇÃO REALIZADA PELO PROJETO PRO-ACORDA? }\end{array}$ & 3 & 5 \\
$\begin{array}{l}\text { CONSIDERA QUE AAÇÃO FOI VÁLIDA PARA FUTURAS PRÁTICAS DO } \\
\text { ESCRITÓRIO? }\end{array}$ & 3 & 5 \\
\hline OS EXEMPLOS APRESENTADOS FORAM SIGNIFICATIVOS? & 3 & 5 \\
\hline $\begin{array}{l}\text { CONSIDERA QUE ESTE TIPO DE CONHECIMENTO SE FAZ } \\
\text { PERTINENTE PARAA FORMAÇÂO EM ARQUITETURA? }\end{array}$ & 4 & 5 \\
\end{tabular}

Os estudantes relataram a percepção de que os profissionais envolvidos na primeira ação pouco conheciam o conceito de desenho paramétrico, fato confirmado pela resposta dada no questionário. Isto exigiu a explanação sobre as noções básicas relativas a este conceito, o que caracterizou um momento mais expositivo que interativo. Já em relação à segunda ação, pelo fato de a profissional envolvida ter conhecimento prévio sobre o assunto, o que também foi confirmado no questionário aplicado, os estudantes consideraram que houve maior interesse sobre os casos de projeto estudados, a ação ocorreu de modo mais espontâneo e dialogado, o que promoveu uma troca mais qualitativa de experiências acadêmicas/profissionais.

Após esta experiência piloto, com as ações 1 e 2, as demais ações informativas já foram planejadas a partir da lista dos escritórios registrados junto ao Colegiado de Curso como lugares de estágios realizados pelos estudantes da FAURB/UFPel. Foram selecionados, inicialmente, aqueles com no mínimo 5 vagas oferecidas entre 2015 e 2019 e aqueles que tinham oferecido vagas mais recentemente (adotou-se como parâmetro o oferecimento de pelo menos uma vaga no primeiro semestre de 2019). Chegou-se a uma lista de 10 escritórios e 
houve a tentativa de executar as ações informativas apenas a partir do envio de material digital associado a um vídeo e um formulário. Entretanto, o material foi enviado por e-mail e obtiveram-se apenas dois retornos a este envio.

O material digital, além de material explicativo sobre o Projeto, incluía os casos de estudo 4 e 5, mencionados na Figura 5. 0 formulário tinha o propósito de compreender: o nível de conhecimento dos profissionais acerca do desenho paramétrico; se havia algum uso deste conhecimento junto as suas práticas de arquitetura; se os exemplos apresentados pelo Projeto poderiam ser considerados significativos para a compreensão do emprego do desenho paramétrico na arquitetura; e, se haveria interesse em no futuro adotar tal abordagem em suas práticas cotidianas.

Tendo em vista a insuficiência do meio adotado para a realização das ações buscou-se investir na adição de entrevistas, o que passou a demonstrar efetividade.

A tabela 5 apresenta os quantitativos de escritórios até então envolvidos nas ações informativas, associados ao tipo de comunicação empregada e também à identificação daqueles escritórios que declararam ter algum integrante da equipe com formação em desenho paramétrico e/ou fabricação digital. Estão incluídos os dois escritórios anteriormente envolvidos, atingindo 14 escritórios em um total de 28 listados nos registros de estágios, desde 2015. Com isto, 50 \% dos escritórios listados já receberam informações sobre o Projeto e, de alguma maneira, já forneceram informações que permitem refletir sobre as ações até então realizadas e planejar ações futuras no âmbito deste Projeto.

\begin{tabular}{|l|r|r|r|r|r|r|r|r|r|r|r|r|r|r|r|}
\hline ESCRITÓRIOS & A & B & C & D & E & F & G & H & I & J & K & L & M & N & 14 \\
\hline ENVIO DE FORMULÁRIOS E VIDEOS & & & & & & & & & & & & & 10 \\
\hline ENTREVISTAS & & & & & & & & & & & & & \\
\hline DECLARAM TER FORMAÇÃO & & & & & & & & & & & & & & & \\
\hline
\end{tabular}

Deve-se destacar que as entrevistas, para serem viabilizadas com cada caso, foram realizadas em três formatos: presencial (A e B); de maneira remota, síncrona (D e H) e assíncrona (M e N). Entre fevereiro e março de 2021, foram realizadas as duas entrevistas síncronas por meio da plataforma Google Meet. 0 primeiro escritório abordado foi o D, e esteve representado por uma estagiária, aluna da própria FAURB, a qual foi designada para a entrevista pelo sócio diretor, sob a justificativa de que ela seria a pessoa mais indicada para dar informações sobre o tema específico de uso do desenho paramétrico junto ao escritório. A segunda entrevista, nesta mesma modalidade remota, foi realizada com o arquiteto responsável pelo escritório $\mathrm{H}$, profissional que tinha sido contatado anteriormente por e-mail, no segundo semestre de 2020, e que havia sido um dos únicos a responder ao questionário enviado. Na sequência, foram realizadas as entrevistas de maneira remota e assíncrona, com profissionais dos escritórios $\mathrm{M}$ e N, por meio do WhatsApp, para poder flexibilizar os horários e, acabou por permitir um diálogo estendido. Houve, nestes casos, complementações de perguntas e respostas em tempos diferentes, com envio de imagens para ilustrar os exemplos de projetos citados na conversa. A seguir são sintetizadas as informações/percepções extraídas das entrevistas da modalidade remota, devendo-se ressaltar que nesta modalidade foi possível compatibilizar também os horários com os demais pesquisadores associados ao projeto, agregando-se a participação/contribuições/interações com todo o grupo.

A representante do escritório D (estagiária) relatou que seu primeiro contato com o desenho paramétrico se deu pela exploração por conta própria para resolver um problema de Projeto no âmbito de uma disciplina da grade curricular denominada de Atelier Vertical - Processos Projetuais, do curso de arquitetura da FAURB, (Faculdade de Arquitetura e Urbanismo) da UFPel. No entanto, comentou que ainda não teve a oportunidade de utilizar e aplicar no estágio que desenvolve neste escritório.
Tabela 6. Dados relativos às ações informativas desenvolvidas nos escritórios locais.

Fonte: Autores 
$\mathrm{O}$ arquiteto responsável pelo escritório $\mathrm{H}$, em sua entrevista, reafirmou o que já tinha respondido no questionário enviado por e-mail, em relação ao seu conhecimento sobre o projeto paramétrico. Destacou que em seu escritório utiliza a tecnologia BIM e que tem pouco conhecimento sobre outras aplicações da parametria, tal como a modelagem de elementos customizados.

$\mathrm{O}$ arquiteto sócio diretor do escritório $\mathrm{M}$ relatou que, em relação ao uso do desenho paramétrico no escritório, houve uma demanda, no ano de 2020, para o projeto de um banco personalizado para um ambiente externo, em madeira, que atuaria como um elemento focal, idealizado com uma forma orgânica. Respondeu à pergunta sobre seu nível de conhecimento em desenho paramétrico, ele relatou ter sido contemplado por disciplina de primeiro ano, da mesma Faculdade aqui envolvida, com a introdução pelo viés da geometria (representação de superfícies poliédricas e curvas). Destacou que considera importante o investimento nesta abordagem durante toda a formação em arquitetura, mas que por não ter dado continuidade aos estudos, buscou auxílio em vídeo aulas na Internet para poder aplicar no projeto em questão. Exemplificou outras aplicações vislumbradas para a área em que ele está atuando, do paisagismo, tais como painéis para trepadeiras, estruturas metálicas para áreas externas, bancos e mobiliários personalizados, para visar a exclusividade e a diversificação. Em relação à pergunta se esta realidade ainda está muito distante dos escritórios locais, o arquiteto respondeu que não é distante, mas que apenas falta conhecimento a respeito. Em relação ao questionamento sobre as dificuldades em utilizar tal abordagem no escritório, o arquiteto destacou que o cliente muitas vezes deseja um projeto exclusivo e diferenciado, no entanto, a produção tende a ter custo mais elevado do que para um projeto tradicional, existindo então ainda uma barreira na execução. Outra dificuldade que salientou foi a falta de tempo dos profissionais para estudar a o desenho paramétrico e aplicar em seus projetos.

$\mathrm{O}$ arquiteto responsável pelo escritório $\mathrm{N}$ relatou que teve o primeiro contato com esta abordagem em uma disciplina de mestrado, cursada em Lisboa, Portugal, no ano de 2013, de com os professores José Pinto Duarte e José Nunes Beirão, por conta do programa do governo brasileiro Ciência Sem Fronteiras. Em 2020, já como arquiteto, ele desenvolveu um script para um teto curvo a ser construído em seu escritório localizado na cidade de Pelotas, configurado com a técnica de planos seriados. A concepção deste teto contou com atividades de avaliação do desempenho acústico, porém desenvolvidas posteriormente à definição da forma. Tal elemento foi executado por um marceneiro local, com o uso, para o corte das peças, de uma máquina CNC. As imagens da Figura 8 foram disponibilizadas também por whatsApp para ilustrar a descrição realizada durante a entrevista.

Figura 8. Teto curvo projetado e fabricado pelo arquiteto Marcos Pretto

para o seu escritório localizado na cidade de Pelotas.

Fonte: Cedido pelo arquiteto.
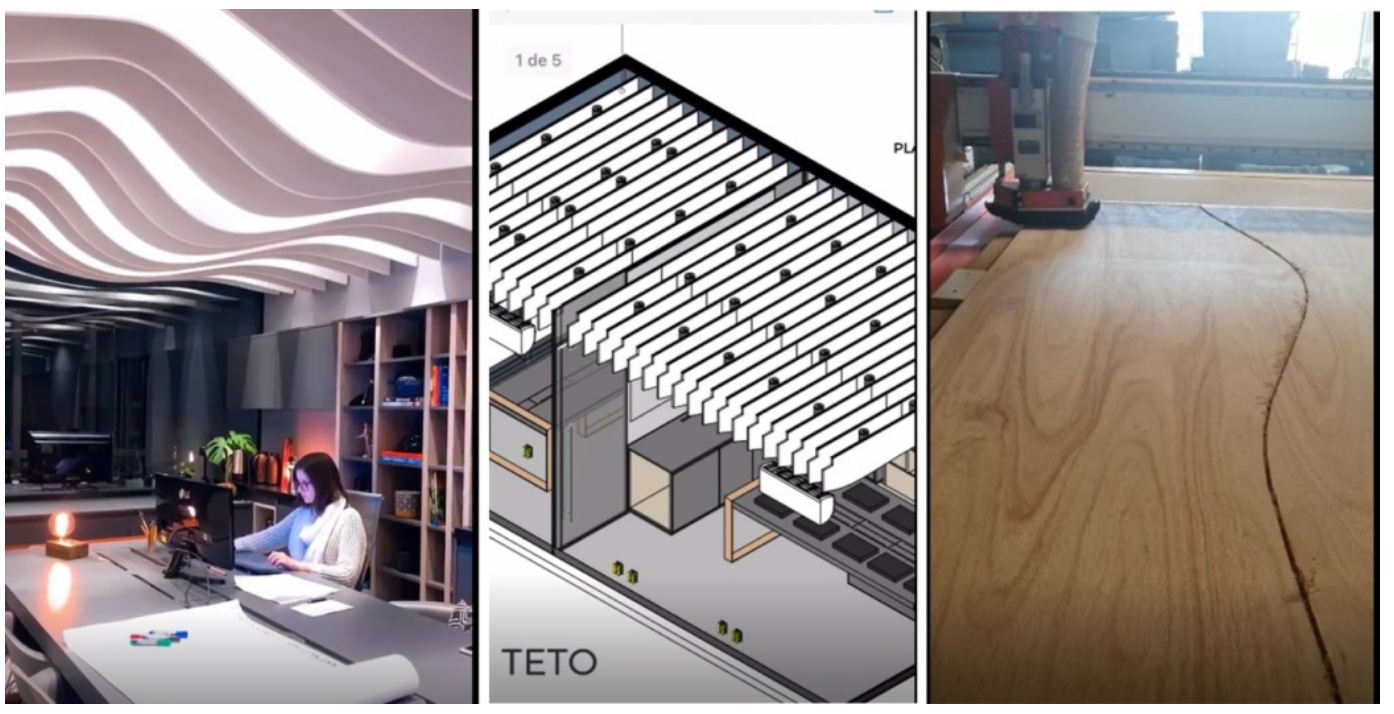
Desenvolvimento das Ações do tipo 3: in-loco

As ações in-loco, como já mencionado, são dependentes do protagonismo de estagiários afetados também pelos propósitos do Projeto. Frente a isto o desenvolvimento deste tipo de ação segue um planejamento flexível e atento às oportunidades de conciliar interesses acadêmicos e profissionais.

Na última edição da disciplina RCE (semestre letivo 2020/02, transcorrido ainda neste primeiro semestre de 2021, pelos transtornos do momento de pandemia) foi possível construir um ensaio de uma ação in-loco, tendo em vista a oportunidade de que o estudante matriculado na disciplina estava paralelamente realizando um estágio junto a um escritório de arquitetura. 0 caso de estudo selecionado (caso 6 da Figura 5) esteve focado na especialidade de produção do escritório que é de paisagismo, e com isto houve um investimento em promover uma formação compartilhada sobre o tema, protagonizada pelo estagiário.

Outro movimento realizado de maneira contínua é o esforço de detectar a manifestação de casos de emprego do desenho paramétrico junto ao cenário de produção arquitetônica e urbanística na cidade de Pelotas. Este esforço tem o propósito de oportunizar outras maneiras de diálogo entre a academia e a prática profissional, propondo talvez parcerias para estas ações in-loco, em locais que já desenvolvem esta cultura de uso de processos paramétricos e de fabricação digital.

O caso detectado, ilustrado pela Figura 9, adveio da contribuição de uma arquiteta recémformada, ex-bolsista no grupo que desenvolve este Projeto, atenta às questões aqui estudadas e atualmente aluna especial de disciplina de mestrado sobre o tema, ministrada por pesquisadora integrante deste Projeto. Trata-se do caso de um painel fabricado em chapas de madeira com a técnica de planos seriados que se encontra na entrada de um edifício no bairro planejado Parque UNA. Buscaram-se informações sobre esta aplicação dos conhecimentos tratados e constatou-se que foi desenvolvido por profissionais situados em outros cenários para além da cidade de Pelotas, sem conexões com o contexto formativo de arquitetura local.
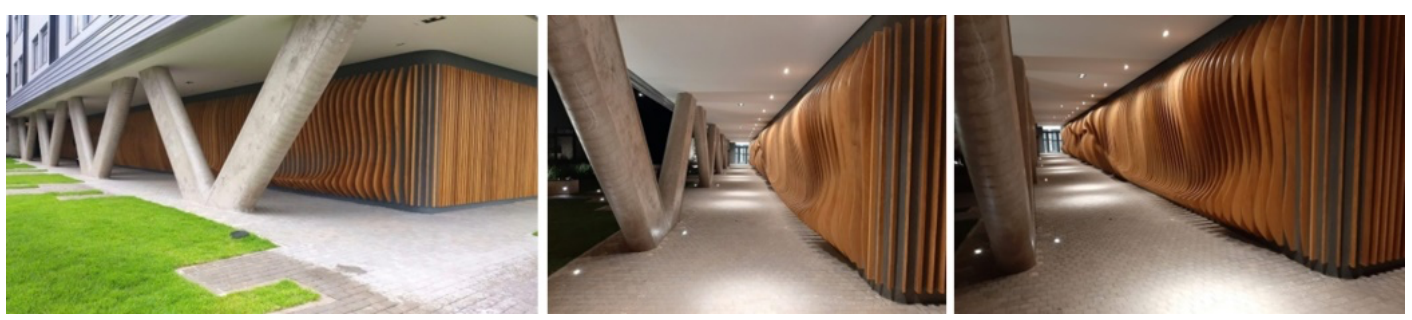

\section{RESULTADOS}

Os resultados aqui apresentados são preliminares considerando-se o todo do Projeto, mesmo que já se tenham dois anos de ações contínuas, formativas e informativas, no âmbito da extensão curricularizada, obtidos entre o segundo semestre de 2019 e o momento de escrita deste texto, em junho de 2021. Entretanto, o avanço para a execução das ações in-loco exige tempo, maior abrangência do processo formativo e repercussões positivas de casos de uso do desenho paramétrico e da fabricação digital, situados no entorno imediato de cada escritório. o Projeto está programado para ser desenvolvido até 2025, na expectativa de que neste tempo seja possível intensificar as interações dialógicas, por intermédio dos estagiários, sobre o tema entre o ambiente acadêmico e o profissional aqui delimitado (lugares que sediam os estagiários da FAURB).

Os profissionais que se manifestaram, por meio dos formulários ou entrevistas, presenciais ou remotas, apontaram para a relevância do Projeto para a disseminação do conhecimento acerca
Figura 9. Painel na entrada de um edifício no Parque UNA, Pelotas.

Fonte: Autores 
do desenho paramétrico. Contudo, construiu-se a percepção frente ao conjunto das informações coletadas que a maioria dos profissionais ainda não parecem ter clareza em como aplicar tal abordagem em seus projetos no dia a dia, o que traz a reflexão também para a academia.

Constituiu-se uma coleção de casos de estudo, significativos para construir um repertório teórico e procedimental sobre o conhecimento aqui particularizado. Entretanto, salvo os estudos sobre a aplicação em um mobiliário, que ilustra a prática que já repercute junto ao entorno imediato dos escritórios abordados (exemplos de um teto, de um banco de jardim, de um painel no espaço de acesso a um edifício) os demais casos são significativos para compreender a potência dos saberes tratados para a resolução de problemas que, aparentemente, ainda estão distantes da realidade local. Mas, ao contrário, os casos acabam por abarcar um conjunto de problemas que podem ser particularizados e situados à escala local de produção. Viu-se que ao exercitar a representação, por exemplo, de elementos que simulam os efeitos lumínicos da cúpula do Museu do Louvre, se constituiu uma maneira didática de traduzir a uma escala que permite vislumbrar outras aplicações, como para a produção de elementos sombreadores, na escala da habitação, o que é mais condizente com o dia a dia dos profissionais envolvidos. Cada um dos casos pode ser pensado desta maneira didática, sendo este enfoque formativo um dos principais resultados do Projeto. Os estudantes são provocados a pensar nas diferentes escalas e realidades de aplicação para serem agentes efetivos de inovação no ambiente acadêmico e profissional.

Entende-se que para avançar no processo deva haver uma imersão continuada dos estudantes no ambiente profissional, sob um olhar focado para detectar problemas a serem associados ao potencial de resolução por meio do desenho paramétrico e da fabricação digital. Frente a isto, considera-se que além da formação no tema, é a postura didática e de investigação, adquirida pelos estudantes, a que pode contribuir para estabelecer uma cultura de aplicação do desenho paramétrico e da fabricação digital junto aos escritórios locais.

Foram alcançados os seguintes resultados previstos no projeto: a estruturação, formatação e disponibilização de processos formativos nas modalidades presencial e a distância; qualificação da equipe envolvida para a docência e consultoria em desenho paramétrico e fabricação digital aplicados ao processo projetual de arquitetura e design; intensificação da interação entre os meios profissional e acadêmico.

\section{CONSIDERAÇÕES FINAIS}

As experiências aqui relatadas têm seus impactos na continuidade do projeto, essencialmente quanto à identificação da necessidade de se desenvolverem atividades conjuntas com os escritórios de arquitetura, no sentido de que seus integrantes possam pensar, propor e operar, eles próprios, a adaptação de seus problemas às teorias, técnicas e tecnologias fundamentadas no projeto paramétrico e na fabricação digital, configurando o seu próprio 'saber-fazer' tecnológico.

Estudos têm sido empreendidos no sentido de compreender como a apropriação de tais tecnologias por grupos sociais tem se efetivado em vários países, principalmente na América Latina, tal como em Scheeren e Sperling (2018). Para os autores, o incremento da produção relacionada às condições específicas de cada região e que representam fatores culturais voltados à resolução de problemas em comum, com novas formas de trabalho e participação, tem sido peça chave para tal efetivação. A ideia, segundo os mesmos autores, seria de não nos limitarmos a simples transferência de tecnologias pré-concebidas, para que não se limite as 
condições de apropriação tecnológica. Os autores consideram que, em vez de copiar saberes e técnicas, a ideia de "reaplicação" é colocada, quando o conhecimento e a tecnologia existentes são ajustados às particularidades de cada local, em que a noção de tecnologia se estabelece como resultado da ação de atores sociais e decisões coletivas. No entanto, considera-se que iniciar o compartilhamento de experiências em desenho paramétrico e fabricação digital, no nível informativo e formativo, a partir de exemplificações das tecnologias e processos préconcebidos e importados de outros contextos sociais, culturais e econômicos, possa auxiliar na disseminação e transposição de tal conhecimento para que ele possa ser adaptado e reconfigurado às condições locais e regionais.

Estes princípios devem então permear as experiências a serem desenvolvidas no futuro do projeto em questão, para que se possam alcançar práticas integradoras e conscientes, emergidas dos próprios escritórios de arquitetura mediante trocas de conhecimento com os acadêmicos e pesquisadores/professores envolvidos.

Outro aspecto a se levar em conta é o espaço que a extensão oferece em oportunizar a troca entre os contextos profissional e educativo, podendo-se refletir do mesmo modo que Llach e Burbano (2020) quando se referem aos polos sul e norte, este último como produtor e exportador de tecnologias e o primeiro como receptor e importador, atentando-se para a necessidade de que os dois polos andem juntos, avaliando e acelerando o processo de reconhecimento dos avanços tecnológicos, em relação à pertinência de estarem permeando tanto as práticas didáticas como profissionais locais. Isto é importante para que nem a academia e nem o meio profissional tenham posturas de transferência de tais saberes e tecnologias, mas sim exista uma retroalimentação, tendo a academia uma postura atenta às expressões locais do uso da tecnologia, atenta aos sujeitos de um entorno específico, buscando fazer visível outras maneiras de inovação e criatividade, sem que haja a expectativa de um enquadramento em padrões tecnopedagógicos acadêmicos ou importados (Llach e Burbano, 2020, p.14).

\section{Agradecimentos}

Às bolsas recebidas (PREC UFPEL), ao CNPq e FINEP pela infraestrutura do laboratório de representação e fabricação digital. Aos escritórios de arquitetura Graphitar, Riemke Arquitetura LTDA, Inflorescência Paisagismo e Marcos Pretto, aos estudantes da disicplina Requisitos Curriculares de Extensão das turmas de 2019 a 2020 da Faculdade de Arquitetura e Urbanismo da Universidade Federal de Pelotas, aos bolsistas do projeto Pro_Acorda da mesma universidade, graduandos, respectivamente, dos cursos de Arquitetura e Urbanismo, Engenharia de Materiais e Engenharia da Computação, entre os anos de 2019-2020.

\section{Referências Bibliográficas}

BORDA, A. A. S.; BRUM, V. Entre a lógica acadêmica e a empresarial: uma experiência de préincubação na área de representação, projeto e fabricação digital. Anais... I Congresso de Inovação Tecnológica da UFPel, 2017, p. 1-4.

BURRY, J; BURRY, M. The New Mathematics of Architecture. London: ed. Thames e Hudson, 2010.

CELANI, G.; SEDREZ, M. Arquitetura Contemporânea e Automação. Prática e Reflexão. São Paulo: ProBooks Editora, 2018.

CELANI, G.; VAZ, C. E. V.; PUPO, R. SISTEMAS GENERATIVOS DE PROJETO: CLASSIFICAÇÃO E REFLEXÃO SOB O PONTO DE VISTA DA REPRESENTAÇÃO E DOS MEIOS DE PRODUÇÃO. Revista 
Janice de Freitas Pires janicefpires@hotmail.com

Adriane Borda Almeida da Silva adribord@hotmail.com

Alexandre Berneira da Silva asberneira@gmail.com

Ramile da Silva Leandro ramileleandro@hotmail.com
O compartilhamento de saberes sobre o uso da modelagem paramétrica e da fabricação digital entre contextos formativos e profissionais de arquitetura: relato de caso

Brasileira de Expressão Gráfica, v. 1, p. 22-39, 2013. Disponível em:

<http://www.fec.unicamp.br/ lapac/publicacoes.htm> Acesso em: 23 Nov. 2020.

CHEVALLARD, Y. La Transposición didáctica. Del saber sabio al saber enseñado. Buenos Aires: Aique Grupo Editor, 1991. 3a ed. 4a reimp. Título original: La transposition didactique. Du savoir savant au savoir enseigné. Grenoble: Pensée Sauvage, 2ème édition, 1991.

CHEVALLARD, Y. El Análisis de las Prácticas Docentes en la Teoría Antropológica de Lo Didáctico. Recherches en Didactique de Mathématiques, Grenoble, 19(2), 221-266, 1999. (Traducción de Ricardo Barroso, Universidad de Sevilla). Disponível em:

<https://edisciplinas.usp.br/pluginfile.php/118315/mod resource/content/1/articulo chevallard T AD 1999.pdf> Acesso em: junho de 2020.

CONSELHO DE ARQUITETURA E URBANISMO DO BRASIL - CAU/BR - Ache um arquiteto. Disponível em: <https://acheumarquiteto.caubr.gov.br/> Acesso em: 28 de março de 2021.

KOLAREVIC, B. Architecture in the Digital Age: Design and Manufacturing. New York: Spon Press, 2003.

LLACH, D.; BURBANO, A. Other Computations: Digital Technologies for Architecture from the Global South. Revista Dearq, n. 27, julho 2020, p. 6-19. Disponível em: < https://revistas.uniandes.edu.co/doi/10.18389/dearq27.2020.01> Acesso em: janeiro de 2021.

PANERO, J.; ZELNIK, M. Dimensionamento humano para espaços interiores. São Paulo: Gustavo Gili, 2014.

PRONK, E. Dimensionamento em Arquitetura. 7ạ. ed. João Pessoa: Editora Universitária, 2003.

SCHEEREN, R.; SPERLING, D. M. Technological appropriation and socio-technical adequacy in South America: applications of digital fabrication in architecture and design. Anais... 22th Conference of the Iberoamerican Society of Digital Graphics, 2018, p. 1-8.

SCHUMACHER, P. The Progress of Geometry as Design Resource. Log, Summer, Londres, 2018. Disponível em: <https://www.patrikschumacher.com/index.htm> Acesso em: Agosto de 2020.

WOODBURY, R. Elements of Parametric Design. London: Routledge, 2010.

UFPel/CONSUN № 13/2015. Plano de Desenvolvimento Institucional. 